\title{
Resilience and Criminal Behaviour Involvement among Juveniles in Malaysia: A Case Study
}

Aisyatul Radhiah Ruslan, Norlizah C. Hassan, Mohd Azmi Mat Yusoff

To Link this Article: http://dx.doi.org/10.6007/IJARBSS/v10-i12/8350 DOI:10.6007/IJARBSS/v10-i12/8350

Received: 10 October 2020, Revised: 15 November 2020, Accepted: 29 November 2020

Published Online: 17 December 2020

In-Text Citation: (Ruslan et al., 2020)

To Cite this Article: Ruslan, A. R., Hassan, N. C., \& Yusoff, M. A. M. (2020). Resilience and Criminal Behaviour Involvement among Juveniles in Malaysia: A Case Study. International Journal of Academic Research in Business and Social Sciences, 10(12), 497-507.

\section{Copyright: (c) 2020 The Author(s)}

Published by Human Resource Management Academic Research Society (www.hrmars.com)

This article is published under the Creative Commons Attribution (CC BY 4.0) license. Anyone may reproduce, distribute, translate and create derivative works of this article (for both commercial and non-commercial purposes), subject to full attribution to the original publication and authors. The full terms of this license may be seen at: http://creativecommons.org/licences/by/4.0/legalcode

\section{Vol. 10, No. 12, 2020, Pg. 497 - 507}

Full Terms \& Conditions of access and use can be found at http://hrmars.com/index.php/pages/detail/publication-ethics 


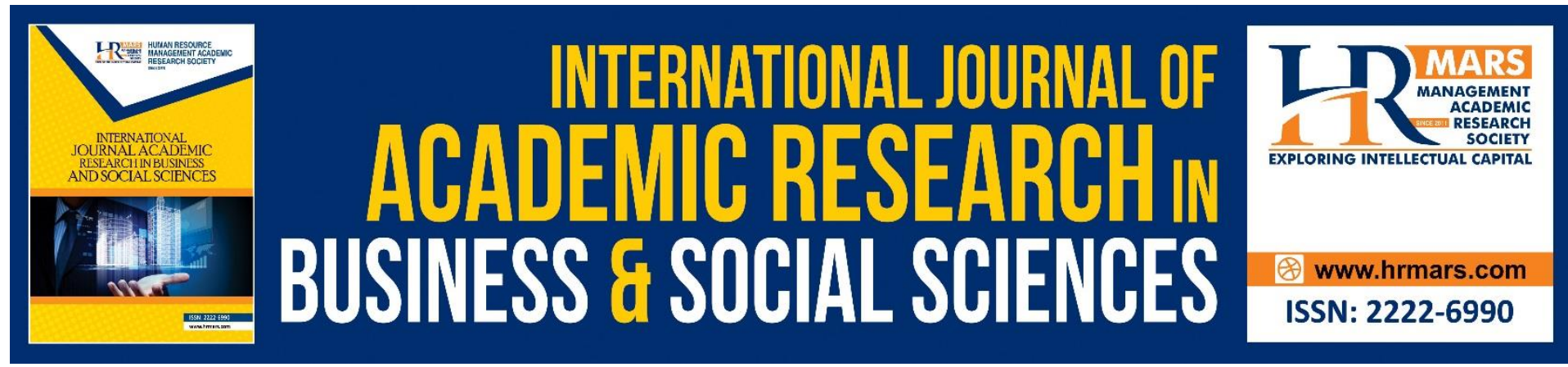

\title{
Resilience and Criminal Behaviour Involvement among Juveniles in Malaysia: A Case Study
}

\author{
Aisyatul Radhiah Ruslan', Norlizah C. Hassan², Mohd Azmi \\ Mat Yusoff ${ }^{3}$ \\ ${ }^{1,2}$ Faculty of Educational Studies, Universiti Putra Malaysia, 43400 UPM Serdang, Malaysia \\ ${ }^{3}$ Institut Pendidikan Guru, Kampus Pendidikan Islam, Bangi \\ Email: aisyatulRR@gmail.com,norlizah@upm.edu.my, azmirr6@yahoo.com
}

\begin{abstract}
Adolescence is perceived as a critical stage in human life. The well-being of adolescents is related to the level of resilience and criminal behaviour involvement among them. Recently, adolescents' level of involvement in delinquency has increased. Therefore, the purpose of this study was to determine the relationship between adolescent level of resilience and criminal behaviour involvement. The study was based on the quantitative method with correlational design using questionnaires adapted from the previous studies. The research instrument of the Personal Resilience Questionnaire was adapted from Warner (2009), and the Youth Delinquency questionnaire from Rozumah (2003). A pilot study was conducted with the Cronbach Alpha score for the Personal Resilience Questionnaire was 0.85 and the delinquent behavioural questionnaires was 0.73 . The sample used in this case study were students in Integrity School (Kajang Prison), Selangor. A simple random sampling was used with a sample size of 132 students chosen as the respondents. The findings indicated that the highest percentage of respondents is at medium level (criminal behaviour), while the lowest percentage is at the low level (criminal behaviour). It was also found that these adolescents have low level of personal resilience. The study also found that there is a significant relationship between the level of resiliency and criminal behaviour involvement. This study gives contribution to the field of study by suggesting that relevant parties can have better understanding on the aspects of adolescent resilience, thus develop effective preventive measures for them.
\end{abstract}

Keywords: Resiliency, Involvement Level, Delinquent Behaviour, Crime, Juveniles

\section{Introduction}

Malaysia has a fairly young population, with 60 percent of its population being below 30 years of age. The general perception amongst stakeholders is that children with offences has increased in recent years and that the types of crimes that children are committing have become more serious. However, assessing patterns of offense is difficult due to gaps in data collection and inconsistencies in statistics collected by the different agencies (Muhammad, 2011). Most of the cases reported by the local news and newspaper involved adolescents and these cases have been a hot topic as the adolescents are an important asset of the nation. 
The well-being of adolescents is related to the level of resilience and level of criminal behaviour involvement among them. There are questions why adolescents are more likely to engage in these social problems. At the stage of growing up, adolescents were always in confusion, sadness and conflict, this might be because at this level, they are still confused with their identities. A psychologist, Erik Ericson describes that an adolescent suffers an identity confusion at this stage (Santrok, 2008). In this age, adolescents are actively seeking their identities and have a very high sense of curiosity. With the confusion faced by these adolescents, they are vulnerable to negative incidents such as delinquency, bullying, stealing, smoking etc. In addition, the adolescent years is a period of time that will determine their future whether they will be in good shape or otherwise. If they suffer from uncertainty or failure in the field that they ought to achieve success, they will probably do other ways to impress the community.

The level of resilience in adolescents is very important in order to avoid them from doing negative things. A term of resilience has been introduced which means the ability of an individual to cope with stress and crisis (Yeager \& Dweck, 2012). Resilience is found to be very important in an adolescent because at this stage, the individual will face life pressure in their process of growing up from children to teenagers and ultimately to adult. There were studies that proved the level of resilience of an adolescent could predict their delinquency behaviour (Donnon, 2010). With high level of resilience, it may be able to reduce or prevent the involvement in delinquency behaviour. Resilience is a term that means ' to bounce back ' from a bad experience or hardship. It is a process of adapting to trauma, tragedy or resources that cause a person to experience stress such as family problems or relationships, severe health problems and so on (Yeager et al., 2012). One study found that delinquency in school occurs when a teenager is under pressure, regardless of the pressure from their family, friends, teachers or their environment, they are unable to cope with the stress well.

Resilience is also more on internal abilities or behaviour that allows an individual to overcome the tribulation or adversity (Jordan, 2009). Resiliency is usually described as:

i. Good results from risky individuals,

ii. Maintaining individual competencies despite under stress

iii. Recovery from trauma.

Delinquency refers to adolescents (juveniles) who do things that are against the norms of society. Most adolescents are high school students. Examples of delinquency that they face are school drop-offs, bullying teachers, bullying friends, smoking and so on. There have been numerous studies on this delinquency (Glowacz \& Buzitu, 2014; Donnon, 2010). In this study, juveniles are adolescents below 18 years old, as prescribed by Malaysian laws and policies, the definition section of the Child Act 2001 states that a "child" means a person under the age of eighteen years and, in relation to criminal proceedings, means a person who has attained the age of criminal responsibility as prescribed in section 82 of the Penal Code. The Penal Code states that children under the age of 10 years are not criminally responsible for their actions. As such adolescent or juveniles in this study range from age of 14-19 years old.

Researchers see that resilience helps an individual to deal with a problem well under stress. A person with high resilience can adapt well and adjust it according to their needs (Russo \& Boman, 2007). Resilience can often be seen in an individual's attitude, endurance or self-esteem. A study on resilience has been conducted on adolescents, where the adolescents involved were found to have high resilience levels which promote positive self-development, as well as high involvement with the community (Spano, 2006). It is also reported by other studies that environmental characteristics and individual characteristics lead to resiliency in 
an individual. This study of resilience is not confined to students or adolescents but also to adults. At an adolescent level, an individual experiences difficulty in life and stress through the transition from childhood to adulthood.

It is found that resilience cannot be discussed without the presence of stress and difficulty in life (Luthar, Crossman \& Small, 2015). Adolescents who are depressed and have difficulty in life are categorized as at risk adolescents, they are more likely to be involved in delinquent behaviour (Luthar, et al., 2015). However, not all of them are involved in delinquent behaviour even though they are going through a lot of hardship in their lives. In fact, the researchers have found that these at risk adolescents have a good level of personal resilience (Luthar, et al., 2015). This is supported by previous researches where they found that level of resilience in an adolescent could determine the potential of their involvement in delinquency (Nourian, Shahboulaghi, Tabrizi, Rassouli \& Biglarrian, 2016).

Why do some youth who experience the juvenile detention system succeed after a brief period in detention while others re-engage with the justice system time and time again? This query remains as one of the most important unanswered questions affecting the juvenile justice system. As researchers, it is important to consider this question because it can successfully link treatment policies for juvenile offenders and it is more likely to be more flexible. Resilience in youth who have had previous contact with the juvenile justice system has substantial benefits to the individual and community. Juvenile incarceration is costly and have been the main expenditure that need to be cater by our government. Whereas, we can re-invest those resources into things that are much better, like in-home family counselling, academic support, mentoring, and other positive youth-development approaches, to build on the strengths and assets of young people and not simply focus on their deficits, or the one act of delinquency in their life that forever will mark them. Therefore, this study intends to identify the level of resilience among problematic adolescents (juveniles). The main objective of this study was to study the relationship between levels of resilience and criminal behaviour among juveniles at Kajang Integrity School (Kajang prison), Selangor.

\section{Literature Review}

The nation has been afflicted with juvenile delinquency for a long time. While much has been said and discussed, the topic has not been adequately addressed. The problem of juvenile delinquency is stated to increase from time to time. The number of cases actually reported is estimated to be much higher than that. At the initial stage this delinquency is in the form of abuse of school rules such as truancy, smoking and vandalism. The inability to take appropriate action to mitigate and resolve this, is a cause for more severe crime, including bullying, injuries towards others, abuse, robbery and killing. Effective preventive and rehabilitative measures must be implemented in an integrated and widespread manner at the family and community levels, school and rehabilitation institutions in view of the fact that the younger generation will inherit the nation's wealth, place, profession and leadership (Kassim, 2004; Berdychevsky, Stodolska \& Shinew, 2019).

Resilience research is focused on incorporating what is learned about risk and promoting factors to help people succeed in adversity (Duke \& Borowsky, 2015). Resilience research is essential to the criminal justice system in order to find ways of reducing recurrence rates and reducing overall crime. The theories which are in four place to evaluate resilience are broad and vary widely; the literature has focused on several models and theories: social cognitive theory, which promotes resilience by having youth display positive behaviours learned from observation rather than a predisposal to negative self-belief (Bandura, 1999; 
Bronfenbrenner, 1979, in Boon, Cottrell, King, Stevenson, \& Millar, 2012) Ecological model which states that we are influenced by the systems in our environment, from our individual self, to our home, neighbourhood, community, all the way through to being influenced by the cultures, beliefs, and laws set forth by our governments; this influence can confer resilient behaviours when faced with community adversity during times of natural disaster (Boon et al., 2012).

\section{Methodology}

This study is a quantitative descriptive study of correlations that examines the relationships between variables. The samples involved in this study were students or adolescents with juvenile cases and are currently undergoing rehabilitation at Kajang Integrity School (prison), Selangor. The population of this study is students from Kajang Integrity School aged 14 to 19 years old. The respondents consisted of male juvenile prisoners only. The sample used in this study was simple random sampling and the sample was taken according to the Sample Size Determination Table by Krejcie and Morgan (1970), where for a population of 153 people, 132 respondents were required to be involved. There were two instruments used in this study, first, instrument to measure adolescent delinquent behaviour which was developed by Rozumah (2003). Second, instrument used to study adolescent's resiliency that was developed by Warner (2009). Both instruments used likert scale of 1 to 5 (Personal Resilience Questionnaire) and Likert scale of 1 to 4 (Criminal behaviour). The instruments have been translated into Malay version and a pilot study was conducted with the Cronbach Alpha score for the Personal Resilience Questionnaire was 0.85 and the delinquent behavioural questionnaires was 0.73 .

\section{Results and Analysis}

The age distribution of respondents ranged from 14 years to 19 years old. Three $(2.3 \%)$ respondents were 14 years old, five (3.8\%) were 16 years old, 11 (8.3\%) were 17 years old, 20 (15.2\%) were 18 years old and 93 (70.5\%) were 19 years old years. It was found that 19 -yearold respondents had the highest percentage while 14-year-old respondents had the lowest percentage. The respondents were mostly adolescents that had been sentenced for a long time before this study was conducted. The youngest adolescents in this prison (Integrity School) were 14 years old, therefore, the sample choose were adolescents aged 14 to 19. Although, there are also prisoners aged 20 and above, but this study only focused on the adolescents below 20 years old.

The finding of the study showed that the respondents' fathers' occupation can be categorized into three: self-employed, employed and unemployed. The self-employed fathers were 69 (52.3\%), the employed fathers were 55 (41.3\%) and the unemployed fathers were eight (6.1\%). In summary, the highest percentage of occupations were the self-employed fathers at $52.3 \%$ and the lowest percentage were unemployed fathers at $6.1 \%$ ).

The respondents' mothers' occupations were categorized by the researcher as selfemployed, employed and unemployed. It was found that $28(21.2 \%)$ mothers were selfemployed, 35 (26.5\%) were wage earners and 69 (52.3\%) were unemployed. The finding of the study showed that the working mothers of the respondents had the highest percentage while the self-employed mothers had the lowest percentage.

Meanwhile, father's distribution of education level showed that $41(31.1 \%)$ of the fathers had UPSR, 60 (45.5\%) of the fathers had PMR, 27 (20.5\%) had SPM, three (2.3\%) had STPM or Diploma and $1(0.8 \%)$ had a degree. The data of this study indicated that the highest 
education level with the highest percentage is PMR and the lowest percentage is the father with a degree. The distribution of the highest level of education of respondents' mothers was found that 50 (37.9\%) of the mothers had UPSR, 65 (49.2\%) had PMR, 16 (12.1\%) had SPM and $1(0.8 \%)$ had STPM or Diploma. The findings show that the highest percentage of the highest education level is PMR and the lowest is the mother with STPM or Diploma.

Table 1 below shows the distribution of respondents' personal level of resilience. It was found that $1(0.8 \%)$ of the respondents were very resilient, $10(11.8 \%)$ of the respondents were resilient, $106(80.9 \%)$ of the respondents were almost resilient and $15(7.8 \%)$ of the respondents has low resilience level. It was found that the highest percentage of respondents' personal resilience was at the level of almost resilience while the lowest percentage was at low resilient.

Table 1: Distribution of Respondents' Personal Level of Resilience

\begin{tabular}{lll}
\hline Personal level of resilience & $\mathbf{N}$ & Percentage (\%) \\
\hline Very Resilient & 1 & 0.8 \\
Resilient & 10 & 11.8 \\
Almost Resilient & 106 & 80.9 \\
Low Resilient & 15 & 7.8 \\
Total & 153 & 100 \\
\hline
\end{tabular}

According to Warner (2009), those who are at the level of very resilient stage (0.8\%) can enjoy their life to the fullest. They can handle the hardships and the difficulties in a good way as well as enjoying lives. Individuals at this level enjoy their lives well and will work harder to improve themselves. At the second highest level of resilience, only $11.8 \%$ of the respondents scored this level, which is only 10 . Individuals at this stage are able to cope with difficult times, challenges and positive changes. They have a specific strategy and are capable of enjoying happiness despite adversity. But according to Warner (2009), they need to consider the development of the principles listed.

In the third level of resilience, $80.9 \%$ of the respondents scored within this range were 106 respondents. It was found that respondents at this stage had strategies to use in dealing with difficult times but unfortunately these strategies did not help these individuals to deal with the demands of difficulty consistently and effectively. Meanwhile, the lowest level of personal resilience, $7.8 \%$ of the respondents, of which 15 respondents. According to Warner, individuals at this level are unable to cope well with change, difficulties and periods of distress which in turn will make the individual at this stage feel very disappointed with what he or she is experiencing. In a state of stress, they cannot feel the joy and strength of their lives. They just let the hard days go by without much effort.

Table 2 below shows the distribution of involvement in criminal behaviour among adolescents. It was found that $2(1.5 \%)$ of the respondents were at low level (criminal behaviour). It was found that $93(70.6 \%)$ of the respondents were at average level and 37 (28.2\%) of the respondents were at high level. Overall mean values and standard deviations were 32.20 and 5.40, respectively. The findings showed that the highest percentage of involvement in criminal behaviour was among the lowest (70.6\%) and the lowest percentage of involvement in criminal behaviour was low (1.5\%). Overall mean $=32.20$; Standard deviation $=5.40$; Level $=$ medium; $n=132$. 
Table 2: Distribution Level of Involvement in Criminal Behaviour

\begin{tabular}{lll}
\hline Level of involvement in criminal behaviour & $\mathbf{N}$ & Percentage (\%) \\
\hline Low & 2 & 1.5 \\
Medium & 93 & 70.6 \\
High & 37 & 28.2 \\
Total & 132 & 100 \\
\hline
\end{tabular}

Many studies on adolescents have found that at this stage of adolescence they are in a state of confusion, sadness and conflict. This is probably because at this young age, they are still confused about their identity. This is also supported by psychologist Erik Erickson in which he studied that a teenager experienced identity or identity confusion at this stage (Upreti, 2017). Adolescents develop a personal fable mindset in which they have a high degree of confidence that they are unique and will not be influenced by the law and will result in their self-destructive life. For example, a teenage boy would think that they would not die if they got stuck on the road because they thought they were too young to die. They have unrealistic beliefs and they are unaware of the possibility they will experience when they do something (Upreti, 2017).

Table 3 below shows the value of Sig. (2-tailed) for the relationship between adolescent's level of personal resilience and their level of involvement in criminal behaviour was $p=0.048$. Because the $p$ value was less than 0.05 , it was found that there was a significant relationship between the respondents' personal level of resilience and their level of involvement in criminal behaviour. Whereas the $r$ value (Pearson correlation) for the relationship between respondents' personal resilience level and their level of involvement in criminal behaviour was $r=-0.360$. According to the Davis coefficient, the Pearson correlation of -0.360 is in a weak relationship. Negative values of $r$ values indicated a weak and inverse negative significant relationship between these two variables. This means that the higher the resilience then the lower the delinquent behaviour.

Table 3: Relationship between Adolescent's Level of Resilience and Criminal Behaviour Involvement

\begin{tabular}{llll}
\hline Involvement in criminal behaviour & Frequency & $\boldsymbol{r}$ & $\mathbf{P}$ \\
\hline Level of personal resilience & 153 & $-.360^{*}$ & .048 \\
\hline
\end{tabular}

* significant at 0.05

This is consistent with Donnon's (2010) study, students with low level of resilience are more likely to be involved in delinquency behaviours than students with high level of resilience. According to Mowder, Cummings and McKinney (2010), juvenile detainees are vulnerable to negative activity. The involvement of teenagers today in criminal behaviour is highly emphasized by the government to address it. The level of adolescents' personal resilience has been found to be important in ensuring that today's adolescents can adapt their lives positively.

From this study, it was found that $90.9 \%$ of juveniles in Kajang Integrity School had third and fourth levels of personal resilience, namely almost resilience and low level of resilience. This shows that many of these adolescents are involved in delinquency because their level of personal resilience does not help them in their life. It is also found that these adolescents have low level of personal resilience. This proves that adolescents involved in 
juvenile cases have low level of personal resilience and were unable to cope with their own difficulties in life (such as conflicts with parents, financial problems, peer pressure, etc.).

\section{Discussion}

The factors underlying juveniles' resilience are still being discovered and more need to be done. However, the findings of this study can contribute to the field of youth education by providing information on adolescent resiliency today. This study highlights the importance of understanding in the development of adolescent psychology in which they will one day lead the nation. This will also ensure future generations will go through development not only cognitively but psychologically as well. This study is very useful for the country's educational institutions in addressing today's widespread social problems. As many researchers have proven that a person's level of personal resilience can be nurtured, it may be possible for our country's education system to include resilience in the hidden curriculum for future students to apply.

This study describes principles that can help an individual to increase their level of personal resilience. Perhaps this can be used by teachers to identify their students' strengths and weaknesses and indirectly encourage the development of their students' personal level of resilience. Parents can also be the catalyst for their child in the development of personal resilience. In addition, this study can also have important implications on the country's education system where models in education can be adapted to enhance resilience by changing the classroom environment (Nickolite \& Doll, 2008). It can be started by conducting a Class-Maps Survey where students will measure classroom environment based on six protective factors, including supportive peer relationships, academic efficacy, academic selfdetermination, self-control behaviour, teacher- student relationships, and home - school relationships. The most important thing teachers need to know is to understand how students' personal resilience develop and what steps teachers need to take in creating a classroom environment that promotes resilience.

According to Mansfield, Beltman, Broadley and Fell (2016), authorities need to pay attention to the teachers' training on which techniques they need to use in the classroom related to resilience. These techniques are fundamental to the theory of self-esteem and selfefficacy which is ideal for promoting the development of student's resilience. This study proposes to teen parents that they can help their children develop their children's personal level of resilience. This may be practiced since they are young, to help them cope with the difficulties and difficulties they will face in their future. It is found that parents who pay attention and support their children, will influence the children from the delusions of delinquency, especially the girls (Glowacz \& Buzitu, 2014; Mughal, 2019). This study also recommends that teachers should foster the development of their student resilience as these students spend 8 hours a day in school. When they were in school, teachers act as substitute to their parents. Teachers, therefore, are the second most important individuals in promoting the development of their students' personal resilience.

For the Ministry of Education, they need to incorporate this element of resilience into the education curriculum. The Ministry of Higher Institution (MOHE) also ensure that future students who are going to be future teachers are well trained and of good quality. These elements may be incorporated into the teaching curriculum for students who will become teachers. The MOHE can also include this element in the hidden curriculum that will be taught to the future teachers. As such, the Ministry of Education Malaysia (MOE) also needs to establish a school psychologist. The aim is to provide parents with techniques to promote the 
development of academic resilience by describing the resilience structure of their children, supporting their children's resilience development and cognitively stimulating their home environment. However, risk factors and consequently, protective and resilience processes, may be different for children, adolescents, and adults, as well as for males and females. Finally, it is useful to distinguish primary resilience (i.e., as a preventive force in the onset of delinquency) from secondary resilience, which refers to a return to a crime-free life after a period of serious offending activity.

\section{Conclusion}

This study of personal resilience should be carried out much more, especially in adolescents. Future researchers may be able to use different research methods and other instruments to measure the level of personal resilience. This is because in identifying adolescent resilience, there might be other principles that can be used to assist in the development of this adolescent's personal resilience. The sample of this study may also be extended to other daily schools as well as to problematic students in government secondary schools. The development of this level of personal resilience may be used by the school in addressing students' discipline problem in school.

This study can contribute to the field of education and review the problems of adolescents in depth. This study provides information on adolescents' personal level of resilience today. This highlights the importance of understanding the development of adolescent psychology in which they will be the nation leader one day. This will also ensure future generations' personal development will go through cognitive and psychological development as well. Cognitive excellence does not guarantee an individual is not involved in criminal behaviour. This is because the internal aspects and resilience of adolescents also need to be emphasized. As well as, promotive and protective factors stem from the community, family, school, peers, and individuals, and the configurations of these factors are important in prevent involvement of the youth in delinquency.

Recently, Covid-19 has affected people globally, young people are no exception. They have been affected by the pandemic as well. In response, government and medical sectors has galvanized and innovated to swiftly meet youth's medical needs, such as through national advocacy efforts and by ramping up telehealth services. We must also remember youth impacted by the justice system. Although it can be easy to forget the plight of adolescents or youth and adults in custody, especially during the COVID-19 global crisis, doing so will threaten the health of youth. Adolescence involved with the justice system are members of these marginalized and vulnerable populations and are entitled to special consideration in response to the COVID-19 pandemic and more likely to have unmet medical, mental health, and social needs; more likely to have been exposed to adverse childhood experiences (ACEs). For the vulnerable youth, the COVID-19 crisis poses considerable risks in the fields of education, employment, mental health and disposable income. Moreover, while youth and future generations will shoulder much of the long-term economic and social consequences of the crisis, their well-being may be superseded by short-term economic and equity considerations. In addition, the closure of schools affects students' (adolescents) mental wellbeing, and the delay or cancellation of exams in around 70 countries, including high-stake final school exams, exposes youth and children to uncertainty, anxiety and stress (UN, 2020). The current situation of covid19 may decrease the resilience behaviour among adolescents, therefore, there are a lot to be done by our government in helping this vulnerable youth by 
enforcing new policies and programmes to enhance youth empowerment and to make sure they are not left behind.

\section{References}

Bandura, A. (1999). Moral disengagement in the perpetration of inhumanities. Personality and Social Psychology Review. [Special Issue on Evil and Violence], 3, 193-209.

Berdychevsky, L., Stodolska, M., \& Shinew, K. J. (2019). The roles of recreation in the prevention, intervention, and rehabilitation programs addressing youth gang involvement and violence. Leisure Sciences. DOI: 10.1080/01490400.2019.1571966

Boon, H. J., Cottrell, A., King, D., Stevenson, R. B., \& Millar, J. (2012). Bronfenbrenners bioecological theory for modelling community resilience to natural disasters. Natural Hazards, 60(2), 381-408. https://doi.org/10.1007/s11069-011-0021-4

Child Act. Laws of Malaysia. (2001). http://www.agc.gov.my/agcportal/uploads/files/Publications/ LOM/EN/Act\%20611\%20-\%2027\%202\%202018.pdf

Donnon, T. (2010). Understanding How Resiliency Development Influences Adolescent Bullying and Victimization. http://ezproxy.upm.edu.my:2214/content/25/1/101.full.pdf

Duke, N. N., \& Borowsky, I. W. (2015). Youth violence prevention and safety: Opportunities for Health Care Providers. Pediatric Clinics of North. Review Article, Volume 62, Issue 5, pp 1137-1158.

Glowacz C., \& Buzitu, M. (2014). 18 away from delinquency and crime: Resilience and protective factors. The Development of Criminal and Antisocial Behavior, pp 283-294.

Jordan J. V. (2009). Relational resilience in girls. Springer link electronic journal http://ezproxy.upm.edu.my:2073/content/j67k758733266230/fulltext.pdf

Kassim, Ab. W. (2004). Juveniles on remand: Trends and practices in Malaysia. United Nations Asia and Far East Institute for the prevention of crime and treatment of offenders Seminar. https:// www.unafei.or.jp/english/pdf/PDF.../13_Malaysia_p196-208.pdf.

Krejcie, R. V., \& Morgan, D. W. (1970). Determining Sample Size for research activities. Educational and Psychological Measurement, 30, 607-610.

Luthar S. S., Crossman, J. E., \& Small, P. (2015). Resilience and adversity. Handbook of Child Psychology and Developmental Science $7^{\text {th }}$ Edition. Wiley Publisher. (pp.247-286). DOI: 10.1002/9781118963418.childpsy307.

Mansfield, F. C., Beltman, S. T., \& Broadley, T., \& Fell, N. W. (2016). Building resilience in teacher education: An evidenced informed framework. Teaching and Teacher Education. Vol 54, 77-87.

Muhammad, R. Ab. R. (2011). The juvenile justice system in Malaysia. $164^{\text {th }}$ International Training Course. https://docplayer.net/56984832-The-juvenile-justice-system-inMalaysia.html.

Mughal, H. A. (2019). Support at Work and its Relationship with Employee Performance: Critical Insights for Early Scholars. Annals of Contemporary Developments in Management \& HR (ACDMHR), 1(3), 16-21.

Mowder, M. H., Cummings, J. A., and McKinney, R. (2010). Resiliency Scales for children and adolescents: Profiles of juvenile offenders. Journal of Psychoeducational Assessment, 28: 326-337.

Nickolite, A., \& Doll, B. (2008). Resilience applied in school: Strengthening classroom environments for learning. Canadian Journal of School Psychology, 23, 94-113. 
Nourian, M., Shahboulaghi, M. F., Tabrizi, K. N., Rassouli, M., and Biglarrian, A. (2016). Resilience and its contributing factors in adolescents in long-term residential care facilities affiliated to Tehran Welfare Organization. International Journal Community Based Nurs Midwifery. 4(4): 386-396.

Rozumah, B. (2003). Keutuhan keluarga dan kesejahteraan anak. Serdang :UPM Press.

Russo R., \& Boman, P. (2007). Primary school teachers' ability to recognise resilience in their students. The Australian Educational Researcher, Volume 34, 1.

Santrok, J. W. (2008). Life-span development. $11^{\text {th }}$ Ed. New York: McGraw-Hill.

Scott, E. (2007). The traits, benefits and development of emotional resilience: Emotional resilience is a trait you can develop.

http://stress.about.com/od/understandingstress/a/resilience.htm

Spano, S. (2006). Risks, protection and resilience. In Handout ACT for Youth Upstate Centre of Excellent. http://www.actforyouth.net/documents/YDM\%20pdf4.1B\%20handout.pdf

UN. (2020). Policy Brief: The Impact of COVID-19 on children, https://un.org.au/files/2020/04/Policy-Brief-on-COVID-impact-on-Children16-April-2020.pdf.

Upreti, R. (2017). Identity construction: An important issue among adolescent. IOSR Journal of Humanities and Social Science, 22(06):54-57.

Warner, R. (2009). Personal Resilience Questionnaire. http://buildingresilience.co.za/

Yeager, S. D., \& Dweck, S. C. (2012). Mindsets that promote resilience: when students believe that personal characteristics can be developed. Educational Psychologist, 47(4), 302314. 